\title{
Modern applications for a total sulfur reduction distillation method - what's old is new again
}

\author{
Gail L Arnold ${ }^{1,2,3^{*}}$, Benjamin Brunner ${ }^{1,2,3}$, Inigo A Müller ${ }^{1}$ and Hans Røy ${ }^{2}$
}

\begin{abstract}
Background: The use of a boiling mixture of hydriodic acid, hypophosphorous acid, and hydrochloric acid to reduce any variety of sulfur compounds has been in use in various applications since the first appearance of this method in the literature in the 1920's. In the realm of sulfur geochemistry, this method remains a useful, but under-utilized technique. Presented here is a detailed description of the distillation set-up and procedure, as well as an overview of potential applications of this method for marine sulfur biogeochemistry/isotope studies. The presented applications include the sulfur isotope analysis of extremely low amounts of sulfate from saline water, the conversion of radiolabeled sulfate into sulfide, the extraction of refractory sulfur from marine sediments, and the use of this method to assess sulfur cycling in Aarhus Bay sediments.

Results: The STrongly Reducing hydrlodic/hypoPhosphorous/hydrochloric acid (STRIP) reagent is capable of rapidly reducing a wide range of sulfur compounds, including the most oxidized form, sulfate, to hydrogen sulfide. Conversion of as little as approximately 5 micromole sulfate is possible, with a sulfur isotope composition reproducibility of 0.3 permil.

Conclusions: Although developed many decades ago, this distillation method remains relevant for many modern applications. The STRIP distillation quickly and quantitatively converts sulfur compounds to hydrogen sulfide which can be readily collected in a silver nitrate trap for further use. An application of this method to a study of sulfur cycling in Aarhus Bay demonstrates that we account for all of the sulfur compounds in pore-water, effectively closing the mass balance of sulfur cycling.
\end{abstract}

\section{Background}

In recent years, it has become evident that the biogeochemistry of sulfur is far more complex than previously thought. There are ample discoveries of so far unrecognized sulfur transformations, such as i) sulfate generation in methanic sediments well below the main sulfate zone, the so-called "cryptic sulfur cycle" [1], ii) potential reduction of sulfate to zero-valent sulfur by methanotrophic archaea that utilize biochemical pathways different from classical bacterial dissimilatory sulfate reduction [2] and iii) the oxidation of reduced sulfur by cable forming bacteria [3], or iv) sulfur cycling in the oceanic crust [4]. These findings highlight three needs: First, the highly sensitive tracing of sulfur transformations with the help of radioactive ${ }^{35} \mathrm{~S}$-labeled

\footnotetext{
* Correspondence: glarnold@utep.edu

'Max Planck Institute for Marine Microbiology, 28359 Bremen, Germany ${ }^{2}$ Center for Geomicrobiology, Department of Bioscience, Aarhus University, 8000 Aarhus, Denmark

Full list of author information is available at the end of the article
}

compounds is more essential than ever; second, progress in our understanding of sulfur cycling without closed sulfur and sulfur isotope mass balances can hardly be achieved because potentially pivotal sulfur pools and fluxes escape our detection, and third, the sulfur isotope composition of sulfur compounds at very low concentrations must become accessible to allow for meaningful interpretations of so far hidden sulfur transformations. With the STrongly Reducing hydrIodic - hypoPhosphorous - hydrochloric acid (STRIP) method (presented here, modified from [5-8]), these needs can be covered to a substantial degree. In the following, it will be demonstrated how the sulfur isotope composition of sulfate at extremely low concentration from highly saline environments can be determined by conventional gas-source isotope ratio mass spectrometry with the help of the STRIP method; it will be shown how the STRIP method can be used for the production of ${ }^{35} \mathrm{~S}$-labeled sulfide from the commonly commercially available ${ }^{35} \mathrm{~S}$-sulfate tracer; and examples 
will be given on how this method can be used to obtain closed sulfur isotope mass balances, as well as for the assessment of undetected sulfur pools.

The use of hydriodic acid (HI) to reduce sulfur compounds can be found in the literature as far back the 1920's [9] continuing to more recent applications, e.g. Shan and Chen [10]. However, HI alone will not liberate all sulfur species, leaving pyrite and organically-bound sulfur behind $[10,11]$. The combination of HI with hypophosphorous acid $\left(\mathrm{H}_{3} \mathrm{PO}_{2}\right)$ and hydrochloric acid $(\mathrm{HCl})$ to convert sulfur species including sulfate to $\mathrm{H}_{2} \mathrm{~S}$ for analysis was first introduced by Luke [5] who used this method to determine the sulfur content of rubber. Many subsequent variations in the following decades adjusted both the initial concentrations and relative proportions of reagents to find an optimal combination that would yield good results while minimizing the amount of the relatively expensive HI used (Table $1 ;[5,11]$ ).

In the realm of sulfur isotope geochemistry, the most commonly referenced work using this method is from Thode et al. [7] who used the STRIP distillation to convert barium sulfate $\left(\mathrm{BaSO}_{4}\right)$ to silver sulfide $\left(\mathrm{Ag}_{2} \mathrm{~S}\right)$ for subsequent isotopic analysis. Simultaneously a method that is similar in its applications but employs a mixture of stannous chloride with phosphoric acid (the Kiba reagent) was developed [12] and subsequently refined [13]. The later advent of the direct conversion of $\mathrm{BaSO}_{4}$ to $\mathrm{SO}_{2}$ for sulfur isotope analysis removed the necessity to covert the $\mathrm{BaSO}_{4}$ to $\mathrm{Ag}_{2} \mathrm{~S}$ for most applications [14]. Besides its application in the conversion of sulfur bearing samples to $\mathrm{Ag}_{2} \mathrm{~S}$ for subsequent fluorination techniques for multiple sulfur isotope analysis (e.g. [15]) the STRIP method has fallen into dis-use. There is a suite of reasons why this should not be the case, examples of which will be presented in this study. The aim of this contribution is not a comprehensive test of the STRIP method as recent publications have been with regards to the chromium (Cr)distillation $[16,17]$ but means to bring this highly useful technique with a complete method description back into view in light of its many potential applications in the realm of sulfur isotope biogeochemistry.

\section{Methods}

\section{Preparation of the reducing reagent}

Preparations of and distillations using the STRIP reagent should be done in a well-ventilated hood. The reducing reagent recipe here follows that of Thode et al. [7]. Note that the concentration reported for hydriodic acid has varied through the years, as well as the chemical formula for hypophosphorous acid reported in the literature (Table 1). With regard to the concentration of hydrochloric acid used in the preparation of the reagent, existing literature only specifies "concentrated" (Table 1; $[5-8,15])$. The purpose of the hydrochloric acid has been suggested to increase acidity and volume, such that less hydriodic acid is required [11]. In the course of this study, $32 \%, 36 \%$ or $37 \%$ hydrochloric acid has been used at one time or another and no difference in the performance of the reagent has been observed.

The reagent should be prepared under a stream of nitrogen $\left(\mathrm{N}_{2}\right)$ or other inert gas to avoid oxidation with $\mathrm{O}_{2}$. The reagent preparation will generate a lot of acid fumes, thus the flask top must be firmly set and clamped in place (or it will pop up during the boiling and spit hot acid around) and a water trap, ideally a gas wash bottle, should be connected to the outlet of the flask (Figure 1). In a $1000 \mathrm{ml}$ round bottom flask, $200 \mathrm{ml} \mathrm{HI} \mathrm{(57 \% ),} 100 \mathrm{ml}$ $\mathrm{H}_{3} \mathrm{PO}_{2}(50 \%)$, and $330 \mathrm{ml} \mathrm{HCl}$ (concentrated) are combined, and a small spoonful of boiling stones is added to the flask. The boiling stones should be silicon carbide $[5,18]$ or some other suitably dense material. PTFE boiling chips are unsuitable as they will float on top of the acid mixture. The flask is placed on a heating mantle, the gas lines assembled, and the $\mathrm{N}_{2}$ gas set to as gentle a stream as possible. The mixture is brought to a vigorous boil and boiled for 60 minutes to remove any sulfur contamination present in the reagents. The mixture should be allowed to cool under the $\mathrm{N}_{2}$ stream. Once the mixture is cool, it

Table 1 Commonly referenced literature for STRIP reagent in sulfur geochemistry and reagent details

\begin{tabular}{|c|c|c|c|c|c|c|}
\hline & Luke, 1943 & $\begin{array}{c}\text { Pepkowitz \& Shirley } \\
1951\end{array}$ & $\begin{array}{c}\text { Thode et al. } \\
1961\end{array}$ & $\begin{array}{c}\text { Forrest \& Newman } \\
1977 \\
\end{array}$ & $\begin{array}{c}\text { Johnston et al. } \\
2007 \\
\end{array}$ & $\begin{array}{c}\text { Arnold et al. } \\
\text { This study }\end{array}$ \\
\hline \multirow[t]{3}{*}{ Hydriodic acid } & $160 \mathrm{ml}$ & $100 \mathrm{ml}$ & $500 \mathrm{ml}$ & $500 \mathrm{ml}$ & $125 \mathrm{ml}$ & $200 \mathrm{ml}$ \\
\hline & s.g. $=1.7$ & $47 \%$ & s.g. $=1.7$ & $48 \%$ & n.o.s. & s.g. $=1.7,57 \%$ \\
\hline & $45 \mathrm{ml}$ & $40 \mathrm{ml}$ & $245 \mathrm{ml}$ & $245 \mathrm{ml}$ & $61 \mathrm{ml}$ & $100 \mathrm{ml}$ \\
\hline \multirow[t]{2}{*}{ Hypophosphorous acid } & n.o.s. & $\mathrm{H}_{3} \mathrm{PO}_{2}$ & $\mathrm{H}_{3} \mathrm{PO}_{2}$ & $\mathrm{H}_{3} \mathrm{PO}_{3}^{*}$ & $\mathrm{H}_{2} \mathrm{PO}_{4}^{*}$ & $\mathrm{H}_{3} \mathrm{PO}_{2}$ \\
\hline & $50 \%$ & $30 \%$ & $50 \%$ & $50 \%$ & n.o.s. & $50 \%$ \\
\hline \multirow[t]{2}{*}{ Hydrochloric acid } & $160 \mathrm{ml}$ & $160 \mathrm{ml}$ & $816 \mathrm{ml}$ & $816 \mathrm{ml}$ & $205 \mathrm{ml}$ & $330 \mathrm{ml}$ \\
\hline & n.o.s. & conc & conc & conc & n.o.s. & $36 \%$ \\
\hline
\end{tabular}

*All references call for the use "hypophosphorus" acid, variations in chemical formula are likely typographical errors. n.o.s. = not otherwise specified, s.g. = specific gravity. 


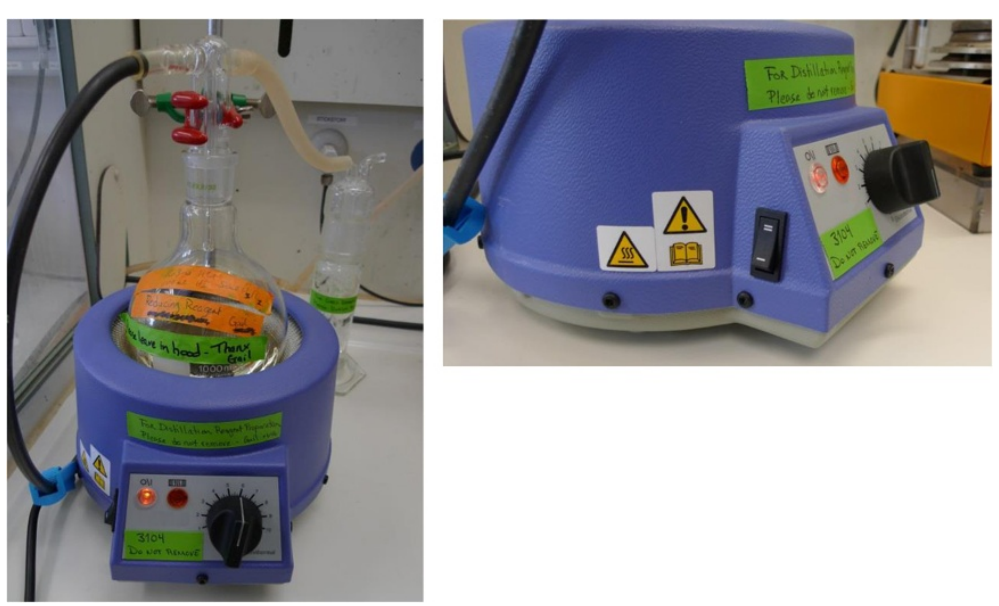

Figure 1 STRIP reagent preparation. The reagent preparation generates a lot of acid fumes, therefore the flask top must be firmly set and clamped in place and a gas wash flask attached to the outlet. With our set-up, we set the switch on the side to the "II" position and the dial to the 6 setting. The unit took approximately 30 minutes to bring the acid to a boil.

should be stored in a brown glass bottle to avoid photooxidation of $\mathrm{HI}[5]$.

As the STRIP reagent may oxidize over time, note the date of the preparation on the bottle and use the reagent within 6 months of its preparation. Smaller batches can be made. Due to the vigorous nature of the boiling, reagent batches should not exceed a total volume of $630 \mathrm{ml}$ per $1000 \mathrm{ml}$ flask.

\section{Preparation of test samples}

All samples, solid or aqueous, processed during the development of this method started from the same commercially available sodium sulfate $\left(\mathrm{Na}_{2} \mathrm{SO}_{4}\right.$, SigmaAldrich Lot \#S23924-206). A sulfate control solution ( $25 \mathrm{mM}$ ) was made by dissolving a known amount of $\mathrm{Na}_{2} \mathrm{SO}_{4}$ in ultraclean water. Method development samples are numbered sequentially and labeled either with a " $\mathrm{C}$ " (for control) or "S" (for standard) prefix. The $\mathrm{C}$ series were run solely for method development. The $\mathrm{S}$ series were run as internal standards during the Aarhus Bay study.

\section{Distillation apparatus}

Samples are distilled in a $100 \mathrm{ml}$ round bottom, 3-neck flask, connected to a condensing reflux column with recirculating chilled $\left(4^{\circ} \mathrm{C}\right)$ water (Figure 2$)$. The outlet of the condensing column is followed by a water trap, which is then followed by the trapping solution. It is advised to keep the amount of tubing between individual glass parts as minimal as possible to limit exposure of tubing to the reagent fumes. First applications of the STRIP distillation were the reduction of sulfur in rubber samples [5], so this mixture may be detrimental to any tubing it comes in contact with. Silicon tubing, which in this study was originally used to connect the outlet of the $1000 \mathrm{ml}$ flask to the gas wash bottle during the preparation of the reagent, was rapidly degraded after a few uses. Viton ${ }^{\circ}$ tubing was used for the connections in the distillation apparatus and has shown the most durability.

\section{Distillation method}

This reagent will reduce all sulfur species (sulfate, sulfide, elemental S, polysulfides, all sulfur intermediate species, and any other sulfur compounds present) of a sample to $\mathrm{H}_{2} \mathrm{~S}$ gas. To begin sample preparation, a sample (aqueous or solid) is transferred into the distillation flask and dried. Aqueous samples that contain sulfide should be fixed with zinc acetate (ZnAc) prior to the drying procedure to avoid degassing of sulfide and/or oxidation of sulfide. The use of ZnAc as the precipitation agent instead of zinc chloride has the advantage that the protons liberated from bisulfide and hydrogen sulfide can form a relatively weak acid (acetic acid) which degasses upon drying. If only chloride is present, the drying procedure could result in a more acidic sample (hydrochloric acid), which - unlike acetic acid - has the potential to liberate sulfide from zinc sulfide. Larger volume aqueous samples or wet sediments can be dried overnight in a $70^{\circ} \mathrm{C}$ oven. Smaller volume aqueous samples may be dried in the distillation flask with gentle heating from the hot plate. The sample must be dried completely such that no water remains. Any water from the sample will condense in the column and drip back into the reagent where it immediately vaporizes due to flash boiling. This and the subsequent rapid condensation of water vapor in the cooling column creates large and dangerous pressure "bumps" and back fluxing of vapors and trap fluids. After drying of the samples, a few boiling stones (see section on preparation of STRIP reagent) are added to the sample flask and the distillation 


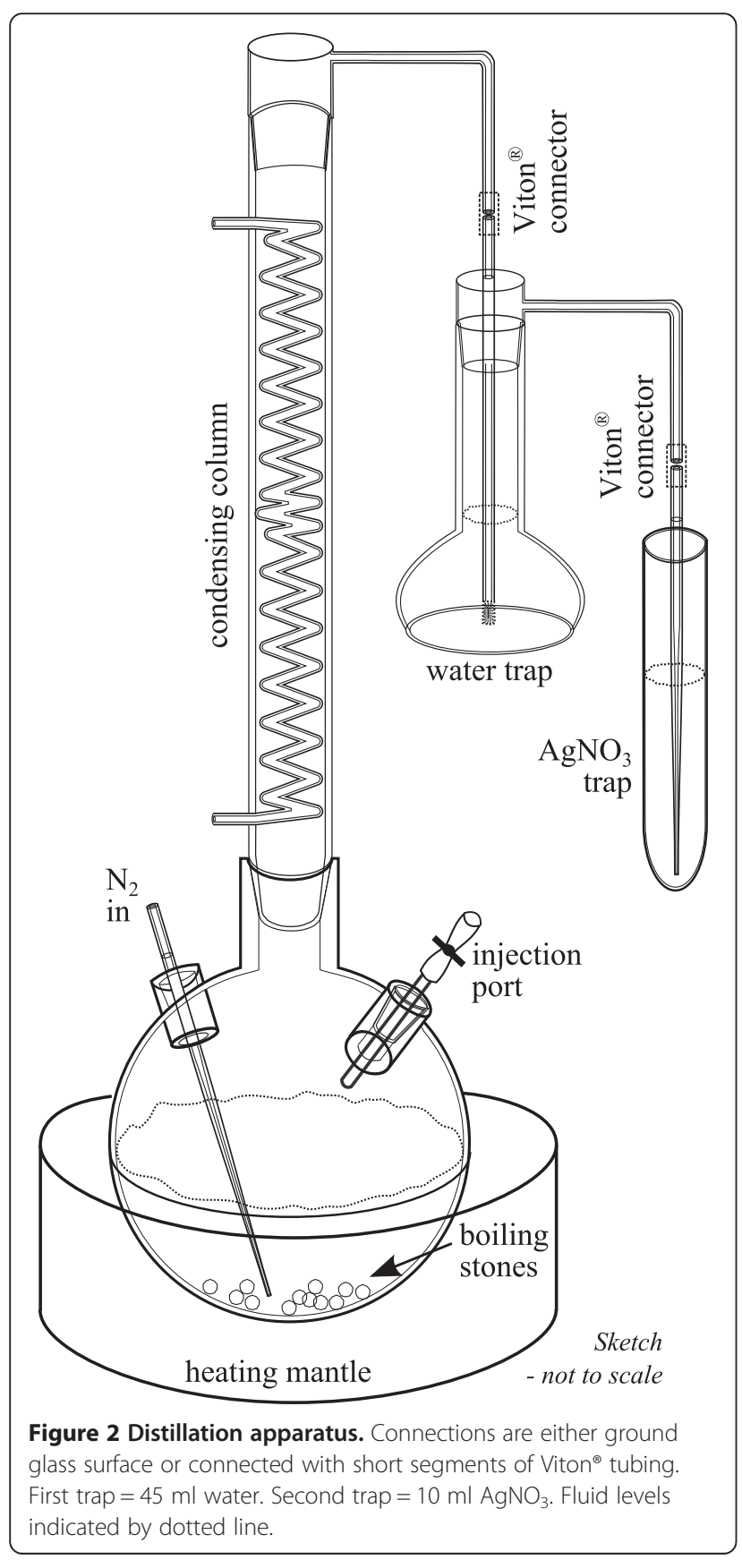

apparatus is assembled, cooling water and $\mathrm{N}_{2}$ gas flow started. Because the acid mixture is brought rapidly to a boil, it is important to make sure that the cooling water has reached a stable temperature prior to heating the sample. Approximately 20 to $30 \mathrm{ml}$ of STRIP reagent are added to the sample via an inlet port on one side of the distillation flask (Figure 2). The reagent-sample mixture is then brought to a boil as swiftly as possible. Distillation at low temperatures will result in lower yields [5]. Once the sample-reagent mixture is boiling any sulfur present is reduced to $\mathrm{H}_{2} \mathrm{~S}$. The evolved $\mathrm{H}_{2} \mathrm{~S}$ and acid fumes are transported by the $\mathrm{N}_{2}$ gas stream first into the water trap which serves as a trap for acid fumes and subsequently into a $10 \mathrm{ml} 1 \mathrm{M} \mathrm{AgNO}_{3}$ trap where the $\mathrm{H}_{2} \mathrm{~S}$ is trapped and converted to $\mathrm{Ag}_{2} \mathrm{~S}$. Despite the presence of a water trap, a certain amount of acid fumes (likely $\mathrm{HI}$ ) will make it to the silver nitrate $\left(\mathrm{AgNO}_{3}\right)$ trap, increasing the apparent $\mathrm{Ag}_{2} \mathrm{~S}$ yield. The excess precipitate is grey/black in color and is not dissolved with $\mathrm{NH}_{4} \mathrm{OH}$ suggesting that the excess is not $\mathrm{AgCl}$, but may be something else, for instance AgI or a phosphorus compound. Samples are distilled for 1 hour, after which the hot plate is turned off and the $\mathrm{N}_{2}$ flow in maintained for another hour to 1) allow the very hot boiling acid to cool sufficiently to handle safely and 2) to ensure that all $\mathrm{H}_{2} \mathrm{~S}$ in the system has been carried to the final trap. Once cool, the $\mathrm{AgNO}_{3}$ trap is removed and the $\mathrm{Ag}_{2} \mathrm{~S}$ is separated and thoroughly washed with ultra-clean water and dried. We recommend turning off the $\mathrm{N}_{2}$ flow only after the traps have been removed from the distillation assembly. This ensures that there is no back-aspiration of fluids resulting in loss of sample.

\section{Quantification of distilled sulfur and isotope analysis}

The STRIP distillation samples always have greater apparent $\mathrm{Ag}_{2} \mathrm{~S}$ yields than is predicted from the amount of sulfur distilled. For the determination of the sulfur isotope compositions of pure substances, i.e., $\mathrm{Na}_{2} \mathrm{SO}_{4}$, $\mathrm{BaSO}_{4}$, or $\mathrm{Ag}_{2} \mathrm{~S}$ standards, 0.2-0.4 mg are weighed into tin capsules. Approximately $0.5 \mathrm{mg}$ of vanadium pentoxide $\left(\mathrm{V}_{2} \mathrm{O}_{5}\right)$ is added to both standards and samples. Greater amounts are weighed in for the STRIP distillation samples. First, the weight of the entire ' $\mathrm{Ag}_{2} \mathrm{~S}$ ' precipitate is recorded and then an appropriate aliquot of sample is weighed into the tin capsule. For example, with samples of known sulfur content such as porewaters where the sulfate and sulfide concentrations have been determined prior to the preparation of the isotope analysis samples, if the predicted mass of $\mathrm{Ag}_{2} \mathrm{~S}$ is $1.0 \mathrm{mg}$ but $3.0 \mathrm{mg}$ of precipitate are recovered, we then know that the $\mathrm{Ag}_{2} \mathrm{~S}$ in the sample is diluted by a factor of 3 , thus 3 times more sample needs to be weighed in $(0.9 \mathrm{mg}$ instead of $0.3 \mathrm{mg})$. This technique has its limitations as the amount of sample that can fit in a tin cup is limited. Up to $2.0 \mathrm{mg}$ of precipitate has been run as a single sample with no detectable ill-effects such as poor combustion, double peaks or extended peak tailing during isotopic analysis. For samples where the sulfur content is not known at the time of isotopic analysis, a second single-step Cr-distillation can be used to purify the STRIP method precipitate $[17,19]$, yielding only $\mathrm{Ag}_{2} \mathrm{~S}$, which can then be weighed in as appropriate. The samples and standards were combusted with an elemental analyzer (EURO EA Elemental Analyzer, set to $1060^{\circ} \mathrm{C}$ ) to produce $\mathrm{SO}_{2}$. A helium stream carried the evolved $\mathrm{SO}_{2}$ through a 
GC column and Finnigan Conflo III into a Finnigan Delta $\mathrm{V}$ stable isotope ratio mass spectrometer (IRMS). The sulfur isotope measurements were calibrated with reference materials NBS $127\left(\delta^{34} \mathrm{~S}=+20.3 \%\right.$ o) and IAEA-SO-6 $\left(\delta^{34} \mathrm{~S}=-34.1 \%\right)$. The standard error $(1 \sigma)$ for replicate measurements of a laboratory standard was less than $0.2 \%$. Quantification of sulfur content is obtained by comparing the integrated peaks areas (in V.s, detected and quantified by IRMS software) samples against the peak areas produced from known amounts of standards, followed by the calculation of the total amount of distilled sulfur from the comparison of the weight of the combusted sample to the total weight of the precipitate.

\section{Results and discussion}

\section{Choice of trapping solution}

The most recent studies using the STRIP distillation method describe the conversion of $\mathrm{BaSO}_{4}$ to $\mathrm{Ag}_{2} \mathrm{~S}$ as a process where $\mathrm{ZnAc}$ is used in place of $\mathrm{AgNO}_{3}$ as the sulfide trap. In a subsequent separate step, the produced $\mathrm{ZnS}$ is then converted to $\mathrm{Ag}_{2} \mathrm{~S}$ which can be used for sulfur isotope analysis via fluorination [15,20,21]. The utilization of $\mathrm{ZnAc}$ as the initial trapping solution is problematic as the acid fumes from the distillation that are not condensed in the cooling column rapidly acidify all subsequent solutions in the distillation including the final trap. If the $\mathrm{ZnAc}$ trap is exposed to acidification, then any $\mathrm{ZnS}$ that had been precipitated will be redissolved and sulfur lost as $\mathrm{H}_{2} \mathrm{~S}$. The use of $\mathrm{ZnAc}$ as the trapping solution was initially tested as part of the development of this study, but sulfur isotope composition results were offset from the known composition and the reproducibility was less than desirable (Table 2). For these reason we moved to the use of $\mathrm{AgNO}_{3}$ as the trapping solution.

\section{Reproducibility of the STRIP distillation method using a $\mathrm{AgNO}_{3}$ trap}

Poor reproducibility was observed when the $\mathrm{AgNO}_{3}$ trap volume was changed from 10 to $5 \mathrm{ml}$. Stoichiometry is not the only consideration when designing the trap volume and concentration. The length and speed at which the $\mathrm{H}_{2} \mathrm{~S}$ travels with the carrier gas $\mathrm{N}_{2}$ through the trap needs be taken into consideration as well. Excessive carrier gas flow or too short a path will result in poorer data reproducibility (Table 3 ).

In order to test the yield and reproducibility of the STRIP distillation method with the appropriate 10 $\mathrm{AgNO}_{3}$ trap, sulfate in varying quantities and form was distilled. Results for the reproducibility and integrity of the STRIP distillation method are summarized in Table 4. Repeated distillations of $1 \mathrm{ml}$ and $0.2 \mathrm{ml}$ of the control solution, 25 and $5 \mu$ mole of sulfate-sulfur, respectively, yielded results of $\delta^{34} \mathrm{~S}_{\mathrm{VCDT}}=-2.5 \pm 0.5 \%$ and $-2.2 \pm 0.3 \%$ o
Table 2 Results of STRIP distillation with $10 \mathrm{ml} \mathrm{5 \%} \mathrm{ZnAc}$ trap

\begin{tabular}{|c|c|c|}
\hline identifier & Amount (mg) & $\delta^{34} S_{\mathrm{VCDT}} \%$ \\
\hline $\mathrm{Na}_{2} \mathrm{SO}_{4}$ (solid, distilled) & 0.212 & -2.3 \\
\hline $\mathrm{Na}_{2} \mathrm{SO}_{4}$ (solid, distilled) & 0.392 & -2.5 \\
\hline $\mathrm{Na}_{2} \mathrm{SO}_{4}$ (solid, distilled) & 0.406 & -2.1 \\
\hline \multirow[t]{3}{*}{$\mathrm{Na}_{2} \mathrm{SO}_{4}$ (solid, distilled) } & 0.230 & -2.4 \\
\hline & Average & -2.3 \\
\hline & stdev (1SD) & 0.2 \\
\hline $\mathrm{Cl}$ & 0.224 & -1.7 \\
\hline C2 & 0.295 & -1.9 \\
\hline C3 & 0.745 & -1.1 \\
\hline C4 & 0.650 & -1.8 \\
\hline C5 & 0.269 & -2.8 \\
\hline C6 & 0.670 & -2.2 \\
\hline C7 & 0.370 & -2.1 \\
\hline C8 & 0.240 & -1.7 \\
\hline C9 & 0.303 & Sample lost \\
\hline $\mathrm{C} 10$ & 0.274 & -2.2 \\
\hline C11 & 0.228 & -2.3 \\
\hline C12 & 0.315 & -1.9 \\
\hline \multirow[t]{3}{*}{$\mathrm{C} 13$} & 0.351 & -1.7 \\
\hline & Average & -2.0 \\
\hline & stdev (1SD) & 0.4 \\
\hline
\end{tabular}

C1 - C13 samples are all from a STRIP distillation of $1.0 \mathrm{ml}$ of $\sim 25 \mathrm{mM}$ sulfate solution.

(Table 4), respectively and $-2.3 \pm 0.3 \%$ o collectively. Barium sulfate was directly precipitated from the control solution and directly analyzed, yielding $\delta^{34} \mathrm{~S}_{\mathrm{VCDT}}=-2.4 \pm 0.1 \%$. The solid sodium sulfate was also analyzed directly, yielding a $\delta^{34} \mathrm{~S}_{\mathrm{VCDT}}=-2.9 \pm 0.4 \%$. Peak areas for the $\mathrm{Na}_{2} \mathrm{SO}_{4}$ solid were $23 \%$ smaller than the average for either $\mathrm{Ag}_{2} \mathrm{~S}$ or $\mathrm{BaSO}_{4}$ standards, indicating poor combustion in the reactor, likely contributing to the shifted sulfur isotope composition of the $\mathrm{Na}_{2} \mathrm{SO}_{4}$ relative to the $\mathrm{BaSO}_{4}$ precipitated from the solution and the $\mathrm{Ag}_{2} \mathrm{~S}$ produced from the distillation of the control solution (Table 4). Regardless of the complications associated with the isotope analysis of solid $\mathrm{Na}_{2} \mathrm{SO}_{4}$, there is no observed offset between the results obtained with the $\mathrm{BaSO}_{4}$ precipitation method and the STRIP distillation.

In summary, the use of $\mathrm{AgNO}_{3}$ as the trapping solution alleviated all problems associated with sample loss and lack of reproducibility. Although $\mathrm{AgNO}_{3}$ as a trapping agent does have the drawback of excess precipitate forming in the trap, the excess mass has not proved at all detrimental to further isotopic analyses and if necessary can be removed by a second distillation using the Cr-distillation $[17,19]$ method. 
Table 3 Results from 5 vs $10 \mathrm{ml} \mathrm{AgNO}_{3}$ trap

\begin{tabular}{|c|c|c|c|c|c|c|c|}
\hline \multicolumn{4}{|c|}{$5 \mathrm{ml} 0.1 \mathrm{M} \mathrm{AgNO}_{3}$} & \multicolumn{4}{|c|}{$10 \mathrm{ml} 0.1 \mathrm{M} \mathrm{AgNO}_{3}$} \\
\hline Identifier & Amount (mg) & Area (V·s) & $\delta^{34} \mathrm{~S}_{\mathrm{VCDT}} \% \mathrm{o}$ & Identifier & Amount (mg) & Area (V·s) & $\delta^{34} S_{\mathrm{VCDT}} \% \mathrm{o}$ \\
\hline S5 & 0.385 & 17.5 & -1.6 & $\mathrm{C} 20$ & 1.943 & 27.6 & -2.6 \\
\hline S6 & 0.399 & 17.3 & -2.0 & $\mathrm{C} 21$ & 1.533 & 27.4 & -2.4 \\
\hline S7 & 0.350 & 7.1 & -1.2 & $\mathrm{C} 24$ & 1.520 & 35.6 & -2.0 \\
\hline S8 & 0.383 & 14.0 & -1.7 & $\mathrm{C} 25$ & 1.630 & 37.4 & -2.3 \\
\hline S9 & 0.476 & 20.6 & -1.7 & $\mathrm{C} 32 \mathrm{a}$ & 1.560 & 23.5 & -1.7 \\
\hline S10 & 0.377 & 8.7 & -0.5 & $\mathrm{C} 32 \mathrm{~b}$ & 1.595 & 22.7 & -1.8 \\
\hline S11 & 0.353 & 6.3 & -1.0 & C33a & 1.588 & 26.1 & -2.1 \\
\hline$S 12$ & 0.378 & 10.0 & -0.8 & C33b & 1.582 & 19.0 & -2.3 \\
\hline S13 & 0.423 & 12.4 & -2.0 & $\mathrm{C} 36$ & 2.502 & 43.3 & -2.1 \\
\hline S14 & 0.451 & 17.1 & -3.0 & C37 & 2.562 & 48.4 & -2.2 \\
\hline \multirow[t]{5}{*}{ S15 } & 0.944 & 27.5 & -2.2 & $\mathrm{C} 40$ & 2.388 & 44.3 & -2.4 \\
\hline & & Average & -1.6 & C41 & 2.479 & 49.3 & -2.5 \\
\hline & & stdev (1SD) & 0.7 & $\mathrm{C} 42$ & 2.734 & 59.0 & -2.4 \\
\hline & & & & & & Average & -2.2 \\
\hline & & & & & & stdev (1SD) & 0.3 \\
\hline
\end{tabular}

S \& C series samples are all from STRIP distillation of $0.2 \mathrm{ml}$ of $\sim 25 \mathrm{mM}$ sulfate solution ( $5 \mu \mathrm{mol}$ of total sulfur).

\section{Caveats of the method}

If nitrate is present, the $\mathrm{H}_{2} \mathrm{~S}$ may be oxidized to elemental sulfur in the condensing column [6]. Care should also be taken with samples high in organic matter content as the presence of organic matter makes the distillation reaction more exergonic and earlier applications of this method contained steps to remove organic compounds prior to the addition of the STRIP reagent $[5,6,11]$. It remains unclear whether the initial oxidation of refractory organic compounds prior to the treatment of the sample with the STRIP distillation in early studies was to improve the sulfur yield during distillation or to avoid potentially dangerous distillation conditions.

\section{Examples for the application of the STRIP method}

In the following, we present four different examples in which the STRIP method can be used, and highlight specific adjustments in the methodology that have to be made for obtaining an optimal outcome.

\section{Preparation of low sulfate concentration pore-water samples for sulfur isotope analysis}

At concentrations below $\sim 0.5 \mathrm{mM}$ sulfate, the traditional method of precipitating $\mathrm{BaSO}_{4}$ from a sample of seawater, pore-water, or marine or fresh-water type media by the addition of barium chloride $\left(\mathrm{BaCl}_{2}\right)$ frequently fails. While the use of ion selective resin is useful to preconcentrate sulfate in fresh-water samples [22-24], the resin based method remains unfavorable in marine and marine-type media due to the high and close affinity of the resin for chloride and sulfate. Recently, the use of multiple collector - inductively coupled plasma mass spectrometry (MC-ICPMS) has been developed for the analysis of extremely small quantities of sulfate [25,26]. Although sulfur isotope analysis by MC-ICPMS lowers the detection limit for sulfur isotope analysis by several orders of magnitude (down to $\sim 5 \mathrm{nmol} \mathrm{S}$ ), the sample preparation prior to the MC-ICPMS analysis still requires resin based chemistry and there are less than a handful of facilities that specialize in this instrumentation and methodology [25,27]. The STRIP reagent presented here offers a reliable, straightforward, affordable and widely accessible alternative, which can be even employed when the $\mathrm{BaCl}_{2}$ method or resin pre-concentration method is not useful. As the STRIP reduction-distillation method will reduce all sulfur present in the sample, if other sulfur species (e.g. sulfide) are present, care must be taken to separate the sulfur species prior to the beginning of the distillation. Sulfide that may be present in the sample can be separated from the sulfate through the addition of ZnAc. Directly after sample collection $0.2 \mathrm{ml}$ of $20 \% \mathrm{ZnAc}$ per $1.0 \mathrm{ml}$ sample is added. Sulfide present in the sample will precipitate as solid zinc sulfide $(\mathrm{ZnS})$. The $\mathrm{ZnS}$ and elemental sulfur is separated from the supernatant by vacuum filtration $(0.2 \mu \mathrm{m})$. The supernatant, which at this point should contain mostly sulfate, but may also contain sulfur intermediates such as thiosulfate or sulfite, can then be distilled to $\mathrm{Ag}_{2} \mathrm{~S}$ for further analysis using the STRIP distillation method. If the presence of significant quantities of thiosulfate or sulfite is suspected, these compounds can be removed via acidification. Thiosulfate will disproportionate into sulfur dioxide and elemental sulfur and sulfite will 
Table 4 Summary STRIP distillation results for $\mathrm{Na}_{2} \mathrm{SO}_{4}$

\begin{tabular}{|c|c|c|c|c|c|c|}
\hline Identifier & Amount (mg) & Area $(\mathrm{V} \cdot \mathbf{s})$ & $\delta^{34} S_{\mathrm{VCDT}} \%$ & $\mathrm{mmol} \mathrm{S}$ & Area $/ \mathrm{mmol}$ & \\
\hline $\mathrm{Na}_{2} \mathrm{SO}_{4}$ (solid) & 0.366 & 54.9 & -2.4 & 0.0026 & 21313 & \\
\hline $\mathrm{Na}_{2} \mathrm{SO}_{4}$ (solid) & 0.368 & 57.1 & -2.9 & 0.0026 & 22037 & \\
\hline $\mathrm{Na}_{2} \mathrm{SO}_{4}$ (solid) & 0.386 & 61.7 & -2.8 & 0.0027 & 22709 & \\
\hline $\mathrm{Na}_{2} \mathrm{SO}_{4}$ (solid) & 0.387 & 77.5 & -3.0 & 0.0027 & 28454 & \\
\hline $\mathrm{Na}_{2} \mathrm{SO}_{4}$ (solid) & 0.364 & 87.2 & -2.1 & 0.0026 & 34028 & \\
\hline $\mathrm{Na}_{2} \mathrm{SO}_{4}$ (solid) & 0.481 & 74.8 & -3.2 & 0.0034 & 22088 & \\
\hline $\mathrm{Na}_{2} \mathrm{SO}_{4}$ (solid) & 0.352 & 83.5 & -2.6 & 0.0025 & 33691 & \\
\hline $\mathrm{Na}_{2} \mathrm{SO}_{4}$ (solid) & 0.364 & 71.5 & -3.3 & 0.0026 & 27903 & \\
\hline \multirow[t]{2}{*}{$\mathrm{Na}_{2} \mathrm{SO}_{4}$ (solid) } & 0.489 & 96.4 & -3.1 & 0.0034 & 28001 & \\
\hline & & Average & $-2.8+/-0.4$ & & 26692 & \\
\hline $\mathrm{C}-14\left(\mathrm{Na}_{2} \mathrm{SO}_{4}\right.$, solid, distilled $)$ & 0.524 & 31.7 & -2.3 & & & \\
\hline \multirow[t]{2}{*}{ C-15 $\left(\mathrm{Na}_{2} \mathrm{SO}_{4}\right.$, solid, distilled $)$} & 0.481 & 30.7 & -2.6 & & & \\
\hline & & Average & $-2.5+/-0.2$ & & & \\
\hline $\mathrm{BaSO}_{4}$ (from control solution) & 0.381 & 55.7 & -2.4 & 0.0016 & 34152 & \\
\hline $\mathrm{BaSO}_{4}$ (from control solution) & 0.381 & 55.6 & -2.3 & 0.0016 & 34050 & \\
\hline $\mathrm{BaSO}_{4}$ (from control solution) & 0.474 & 66.5 & -2.6 & 0.0020 & 32764 & \\
\hline \multirow[t]{3}{*}{$\mathrm{BaSO}_{4}$ (from control solution) } & 0.384 & 54.2 & -2.4 & 0.0016 & 32969 & \\
\hline & & Average & $-2.4+/-0.1$ & & 33484 & \\
\hline & Amount (mg) & Area $(\mathrm{V} \cdot \mathrm{s})$ & $\delta^{34} S_{\mathrm{VCDT}} \%$ & mmol S IRMS & Fraction sample weighed in & Distillation yield \\
\hline \multicolumn{7}{|l|}{$1 \mathrm{ml} 25 \mathrm{mM}$ sulfate } \\
\hline C18 & 0.431 & 25.0 & -2.3 & 0.0007 & - & - \\
\hline C19 & 0.590 & 36.8 & -2.9 & 0.0011 & - & - \\
\hline $\mathrm{C} 22$ & 0.429 & 40.1 & -3.4 & 0.0012 & - & - \\
\hline C23 & 0.592 & 57.6 & -2.0 & 0.0017 & - & - \\
\hline C34 & 0.472 & 33.7 & -2.3 & 0.0010 & 0.04 & $96 \%$ \\
\hline \multirow[t]{2}{*}{ C35 } & 0.606 & 47.3 & -2.2 & 0.0014 & 0.06 & $103 \%$ \\
\hline & & Average & $-2.5+/-0.5$ & & & \\
\hline \multicolumn{7}{|l|}{$0.2 \mathrm{ml} 25 \mathrm{mM}$ sulfate } \\
\hline C20 & 1.943 & 27.6 & -2.6 & 0.0008 & - & - \\
\hline C21 & 1.533 & 27.4 & -2.4 & 0.0008 & - & - \\
\hline C24 & 1.520 & 35.6 & -2.0 & 0.0011 & - & - \\
\hline C25 & 1.630 & 37.4 & -2.3 & 0.0011 & - & - \\
\hline C32a & 1.560 & 23.5 & -1.7 & 0.0007 & - & - \\
\hline C32b & 1.595 & 22.7 & -1.8 & 0.0007 & - & - \\
\hline C33a & 1.588 & 26.1 & -2.1 & 0.0008 & - & - \\
\hline C33b & 1.582 & 19.0 & -2.3 & 0.0006 & - & - \\
\hline C36 & 2.502 & 43.3 & -2.1 & 0.0013 & 0.26 & $100 \%$ \\
\hline C37 & 2.562 & 48.4 & -2.2 & 0.0014 & 0.29 & $98 \%$ \\
\hline C40 & 2.388 & 44.3 & -2.4 & 0.0013 & 0.35 & $77 \%$ \\
\hline C41 & 2.479 & 49.3 & -2.5 & 0.0015 & 0.30 & $100 \%$ \\
\hline \multirow[t]{2}{*}{ C42 } & 2.734 & 59.0 & -2.4 & 0.0018 & 0.29 & $121 \%$ \\
\hline & & Average & $-2.2+/-0.3$ & & & \\
\hline C-38 (0.02 ml) & 4.165 & 7.9 & -2.0 & 0.0002 & 0.45 & $105 \%$ \\
\hline C-39 (0.02 ml) & 3.899 & 6.9 & -0.9 & 0.0002 & 0.51 & $81 \%$ \\
\hline
\end{tabular}


be converted to sulfur dioxide. The elemental sulfur can then be filtered out and the sulfur dioxide can be degassed from the sample.

\section{Conversion of ${ }^{35} \mathrm{~S}$-sulfate to ${ }^{35} \mathrm{~S}$-sulfide tracer}

Sulfide is a substrate for many oxidative S-cycling processes and an important reactant for the synthesis of other ${ }^{35} \mathrm{~S}$-labeled compounds. The reductive distillation of ${ }^{35} \mathrm{~S}$-sulfate to ${ }^{35} \mathrm{~S}$-sulfide tracer is principally the same as for any other aqueous sulfur distillation, given proper safety measures required for the handling of radioactive materials are taken. An appropriate amount of ${ }^{35} \mathrm{~S}$-sulfate tracer is transferred to the distillation flask, gently dried and distilled. Because the sulfate concentration in the radio-tracer is so low, the STRIP distillation should be performed using a $10 \mathrm{ml}$ or larger de-oxygenated $\mathrm{AgNO}_{3}$ sulfide trap to ensure that $100 \%$ of the converted tracer is trapped. The entire contents of the trap can then be dried into a new distillation flask for a subsequent Cr-distillation $[17,19]$. The adjustment here is that the trapping solution for the Cr-distillation should be changed, because is it preferable to obtain a dissolved ${ }^{35} \mathrm{~S}$ sulfide tracer instead of a solid $\mathrm{Ag}_{2}{ }^{35} \mathrm{~S}$ product. Hence, sodium hydroxide ( $\mathrm{NaOH}$, also de-oxygenated) should be used as the trapping solution. There are two considerations to keep in mind when calculating the volume and strength of the $\mathrm{NaOH}$ solution to be used. First, and most straight forward, is the stoichiometric balance needed to trap and convert the evolved $\mathrm{H}_{2} \mathrm{~S}$ to $\mathrm{Na}_{2} \mathrm{~S}$ in solution. Second, the volume of the trap must be optimized such that the desired activity per volume is achieved. An earlier study directly used $1 \mathrm{M} \mathrm{NaOH}$ as the trapping solution with a STRIP distillation method and reported satisfactory tracer recovery $(\sim 100 \%,[28])$. Our attempts at replicating this yielded results in the 30 to $50 \%$ recovery range. As such, we suggest the use of $\mathrm{AgNO}_{3}$ as the STRIP distillation trap, followed by subsequent conversion to a dissolved tracer form using a Cr-distillation and appropriate trap.

\section{Solid phase samples - sediment and rock}

The analysis of the quantity and sulfur isotope composition of acid-volatile sulfur and chromium-reducible sulfur (CRS) in sediments and rocks ([17] and references therein) is common to many sulfur geochemistry studies. The STRIP distillation can be used for the determination of the sulfur content and isotope composition of bulk sediment and rock samples, or can be used as a final step in a sequential extraction scheme, for example in series with a Cr-distillation step, to determine the refractory/residual sulfur phases. For both rock and sediment, the sample should be well homogenized and ground to a fine powder. Sediment and rock samples high in carbonate content should be de-carbonated prior to distillation. Wet sediment needs to be dried prior to distillation.

We applied the STRIP reagent to marine sediments in a sequential extraction. After thawing, the samples $(\sim 5 \mathrm{~g})$ were covered with $50-100 \mathrm{ml}$ of $2 \mathrm{M}$ sodium chloride solution. Over at least 24 hours, the sediment was repeatedly brought in suspension by stirring. Subsequently, the supernatant was decanted and the sample was washed with deionized water by three consecutive centrifugation-resuspension steps. The sodium chloride leaching step serves to remove sulfate that is not intimately associated with carbonate from the samples. Next, the carbonate in the sample was rapidly dissolved by the addition of hydrochloric acid $(\mathrm{HCl}, 10 \mathrm{M})$ to liberate carbonate associated sulfate (CAS). Addition of $\mathrm{HCl}$ was stopped when no further evolution of carbon dioxide (bubbles) was observed with additional acid treatment. The supernatant was immediately filtered, and a saturated $\mathrm{BaCl}_{2}$ solution $\left(\sim 1.3 \mathrm{M} \mathrm{BaCl}_{2}\right.$ in $\left.0.05 \mathrm{M} \mathrm{HCl}\right)$ was added to induce the precipitation of $\mathrm{BaSO}_{4}$. After minimally 12 hours, the precipitated $\mathrm{BaSO}_{4}$ was recovered by centrifugation and decanting of the supernatant. The $\mathrm{BaSO}_{4}$ was washed with deionized water by three consecutive centrifugation-resuspension steps. For a discussion of the caveats of the CAS extraction methods, see [29]. After the CAS extraction, the sample was thoroughly washed and subsequently dried. Next a singlestep $\mathrm{Cr}$-reduction distillation was performed to obtain Cr-reducible sulfur $[17,19]$. Then the washing and drying step was repeated. Lastly, a STRIP distillation was applied to recover any residual sulfur fraction (RSF). The intriguing outcome of this sequential extraction (Table 5) was that the sulfur isotope composition of CAS and RFSsulfur (average $\delta^{34} \mathrm{~S}=+20.5 \%$ ) were almost identical and close to the composition of seawater sulfate, whereas CRS was strongly depleted in ${ }^{34} \mathrm{~S}$ (average $\delta^{34} \mathrm{~S}=-47.6 \%$ ). We speculate that the residual sulfur pool, only accessible with the STRIP distillation, was marine barite. This would explain the similarity between the sulfur isotope composition of CAS, RSF, and seawater sulfate. From the methodological viewpoint, this result shows that STRIPsulfur accessed a different sulfur pool than CRS, i.e. that no residual pyrite influenced the obtained results. Other

\begin{tabular}{|c|c|c|c|}
\hline Sample & $\delta^{34} S_{\text {CAS }} \%$ & $\delta^{34} S_{\text {CRS }} \%$ & $\delta^{34} S_{\text {RSF }} \%$ \\
\hline $\begin{array}{l}\text { Eastern } \\
\text { Equatorial Pacific } \\
\text { sediments }\end{array}$ & $\begin{array}{l}\text { Carbonate } \\
\text { associated } \\
\text { sulfate }\end{array}$ & $\begin{array}{l}\text { Chromium } \\
\text { reducible } \\
\text { sulfur }\end{array}$ & $\begin{array}{l}\text { Residual sulfur fraction } \\
\text { extracted with } \\
\text { STRIP distillation }\end{array}$ \\
\hline Sediment A & 20.9 & -47.8 & 18.4 \\
\hline Sediment B & 22.1 & -45.8 & 19.5 \\
\hline Sediment C & 21.3 & -49.1 & 20.6 \\
\hline
\end{tabular}


research groups add the STRIP reagent directly to the Cr-reagent after the Cr-distillation is complete and obtain satisfactory results with this technique [18]. At this point, it should be noted that the STRIP reagent will extract all remaining sulfur from a sample in a sequential leaching procedure. Thus, if barite is one of the specifically targeted sulfur phases, a leaching step that is more selective would be indicated, for example the barite dissolution/re-precipitation technique using a chelating agent [30], which could then be followed by the final STRIP step.

\section{Application to Aarhus Bay - a pilot study}

Motivation: Exciting new hypotheses in sulfur biogeochemistry (e.g. [2]) highlight the fact that progress in our understanding of sulfur cycling without closed sulfur and sulfur isotope mass balances can hardly be achieved because pivotal sulfur pools and fluxes may have escaped detection when following standard analyses. Station M1 in Aarhus Bay is a popular sampling site with well characterized rates of both organoclastic sulfate reduction and sulfate reduction coupled to the anaerobic oxidation of methane. We chose this site to apply the STRIP distillation to pore-water samples and assess the sulfur mass balance of this system.

Sampling and analyses: An approximately 2 meter long gravity core was retrieved during a short sampling cruise in May 2011. The core was transported to laboratories at Aarhus University where pore-water was extracted on the same day. The gravity core was subsampled by cutting $20 \mathrm{~cm}$ whole-round sections, one end of the sub-section was capped and the other end was covered tightly with plastic wrap ensuring no air pockets between the plastic foil and sediment surface. Pore-water was extracted using Rhizon ${ }^{\bullet}$ pore-water samplers inserted through a small hole punctured in the plastic wrap (for description and supplier, see p 99-100 in [31]). Porewater volumes extracted ranged from $10 \mathrm{ml}$ from the deepest sample to $\sim 50 \mathrm{ml}$ in the shallowest samples. Once pore-water extraction was complete, the pore-water was split into sub-samples for i) total sulfur concentration and isotope composition, ii) sulfate concentration, iii) sulfide concentration, iv) thiosulfate concentrations and v) sulfate/sulfide/'other' S isotope composition (Table 6). Weights and volumes were noted at every step. Sulfate, sulfide, and thiosulfate concentrations were analyzed by standard methods (ion chromatography [31], diamine/ spectrophotometric methods [32], and bimane/HPLC [33], respectively). Series v samples were treated sequentially to separate sulfide and sulfate from any remaining unidentified S-species in solution. First, $\mathrm{ZnS}$ was separated from the sample by vacuum filtration through a $0.2 \mu \mathrm{m}$ filter. The $\mathrm{ZnS}$ was dried on the filter paper in a $50^{\circ} \mathrm{C}$ oven overnight, after which it was carefully removed from the filter and retained for $\mathrm{S}$ isotope analysis. With a modified vacuum filtration system, the filtrate was directly collected in clean $50 \mathrm{ml}$ vials that were subsequently acidified with $0.1 \mathrm{ml}$ ultraclean $\mathrm{HCl}$, after which the sample was flushed with a 10:90 $\mathrm{CO}_{2}: \mathrm{N}_{2}$ gas mixture for one hour to ensure that no sulfide remains in the sample. Next, a sub-sample was transferred to a centrifuge tube and a saturated solution of $\mathrm{BaCl}_{2}\left(\sim 1.3 \mathrm{M} \mathrm{BaCl}_{2}\right.$ in $\left.0.05 \mathrm{M} \mathrm{HCl}\right)$ was added to precipitate sulfate as $\mathrm{BaSO}_{4}$. The following day, the samples were centrifuged and the supernatant was pipetted off into an open syringe and filtered through a $0.2 \mu \mathrm{m}$ syringe filter into a new centrifuge tube. The $\mathrm{BaSO}_{4}$ precipitate was washed several times, dried overnight in a $50^{\circ} \mathrm{C}$ oven and retained for sulfate-S isotope analysis. Series $i$ and the final filtrate of the series $\mathrm{v}$ samples were dried and distilled using the STRIP distillation with a $5 \mathrm{ml} \mathrm{AgNO}_{3}$ trap.

Sulfur isotope mass balance of pore-water at station M1 in the Aarhus Bay: Total sulfur concentrations, determined via the STRIP distillation method, decrease with increasing depth in the sediment. There is strong agreement between the total sulfur concentrations determined from the STRIP distillation with the sum of the individually measured sulfur pools (sulfate + sulfide + thiosulfate) with less than $10 \%$ discrepancy between the two values throughout the profile (Table 7, Figure 3). The sulfur isotope composition of the 'total sulfur' $\left(\delta^{34} S_{\text {TSmeas }}\right)$ samples also provide a good match with the total sulfur isotope composition calculated $\left(\delta^{34} \mathrm{~S}_{\text {TScalc }}\right)$ from the sulfate and sulfide fractions (Figure 4). Two total sulfur sulfur-isotope composition data points are obvious outliers when comparing $\delta^{34} \mathrm{~S}_{\text {TSmeas }}$ vs. $\delta^{34} \mathrm{~S}_{\text {TScalc. }}$. The calculated total sulfur isotope composition of the sample from $75 \mathrm{~cm}$ shows the greatest deviation from the measured counterpart. This is likely the result of poor sample handling/labeling during the preparation of the sulfate-sulfur isotope sample. First, this sample has a

\section{Table 6 Aarhus Bay sampling scheme}

\begin{tabular}{|c|c|c|c|c|}
\hline & Sample & Container type & Volume (ml) & Treatment \\
\hline $\mathrm{i}$ & Total S & Clear glass vial & 1.5 & $0.25 \mathrm{ml} 20 \% \mathrm{ZnAc}$ \\
\hline ii & Sulfate concentration & Cryovial & 0.5 & Flushed with $\mathrm{CO}_{2}$ to remove sulfide \\
\hline iii & Sulfide concentration & Clear glass vial & 1 & $0.20 \mathrm{ml} 20 \% \mathrm{ZnAc}$ \\
\hline iv & Thiosulfate and sulfite & Brown glass vial & 0.5 & Bimane \\
\hline V & Sulfate/sulfide/'other' S isotope composition & $\mathrm{N}_{2}$ flushed $50 \mathrm{ml}$ glass crimp top vial & $>10 \mathrm{ml}$ & $2 \mathrm{ml} 20 \% \mathrm{ZnAc}$ \\
\hline
\end{tabular}


Table 7 Summary of results from the Aarhus Bay pore-water study

\begin{tabular}{|c|c|c|c|c|c|c|c|c|}
\hline Sample ID & Depth $(\mathrm{cm})$ & Total sulfur (mM) & Sulfate (mM) & Sulfide $(\mathrm{mM})$ & Thiosulfate (mM) & $\delta^{34} S_{\text {TSmeas }} \%$ o & $\delta^{34} \mathrm{~S}_{\mathrm{SO} 4} \%$ & $\delta^{34} S_{H S-} \%$ \\
\hline 1 & 15.0 & 20.9 & 19.0 & 0.3 & 0.011 & 25.5 & 26.5 & -31.6 \\
\hline 2 & 45.0 & 16.2 & 12.9 & 2.3 & 0.000 & 31.5 & 41.0 & -29.1 \\
\hline 3 & 75.0 & 12.5 & 9.2 & 3.1 & 0.011 & 34.0 & 41.1 & -17.8 \\
\hline 4 & 112.3 & 9.1 & 4.8 & 3.8 & 0.016 & 31.6 & 59.2 & -4.6 \\
\hline 5 & 126.0 & 6.5 & 3.3 & 4.1 & 0.008 & 33.2 & 64.7 & 0.1 \\
\hline 6 & 141.0 & 5.6 & 1.9 & 3.9 & 0.014 & 28.5 & 71.8 & 5.4 \\
\hline 7 & 156.0 & 4.3 & 0.8 & 4.0 & 0.012 & 24.6 & 84.7 & 11.2 \\
\hline 8 & 171.0 & 3.8 & 0.08 & 4.0 & 0.011 & 16.8 & - & 15.7 \\
\hline 9 & 185.8 & 3.4 & 0.02 & 3.6 & 0.018 & 15.9 & - & 16.1 \\
\hline 10 & 199.5 & 2.7 & 0.07 & 2.8 & 0.023 & 14.6 & - & 15.0 \\
\hline
\end{tabular}

-Samples below $150 \mathrm{~cm}$ did not produce enough $\mathrm{BaSO}_{4}$ for sulfur isotope analysis.

nearly identical sulfate-sulfur composition as the sample from $45 \mathrm{~cm}$ (Figure 3). Second, because the volume and weight is recorded at every stage of sample preparation, we can gravimetrically back-calculate the pore-water sulfate concentration for any $\mathrm{BaSO}_{4}$ sample that was prepared. When this is done for the $75 \mathrm{~cm}$ sample a sulfate concentration of $14.4 \mathrm{mM}$ is obtained, again nearly identical to that calculated for the $45 \mathrm{~cm}$ sample (14.5 mM calculated, $12.9 \mathrm{mM}$ measured) and far removed from the measured sulfate concentration for the $75 \mathrm{~cm}$ sample $\left(\left[\mathrm{SO}_{4}\right]=9.2 \mathrm{mM}\right.$, Table 7$)$. Together, these observations strongly indicate that sulfate-sulfur isotope sample at $75 \mathrm{~cm}$ is corrupted, which comprises the $\delta^{34} \mathrm{~S}_{\text {TScalc }}$ value and so we neglect this sample from further consideration.

Looking at the remaining data, we are still left to consider an outlier at $126 \mathrm{~cm}$ and the general observation that although the rest of the data fall within two standard deviations of the expected 1:1 trend (Figure 4), half of the data lie at the very edge of the error margin. At first glance, this deviation might give the impression that an unidentified sulfur pool exists that contributes to the shift in $\delta^{34} \mathrm{~S}$. However, if we consider the total sulfur concentrations for these samples it becomes evident that the concentrations of the total sulfur samples are smaller than the sum of the sulfur species, the opposite of what one should observe if a 'missing' sulfur pool existed in this depth range (Table 8, Figure 3). In addition, there is the observation that the sulfur isotope compositions of total sulfur are heavier (Table 8; Figure 4) than the value of the sum of all species. With the caveat that we cannot predict the isotope fractionation processes for biochemical reactions between unknown sulfur pools and yetundeciphered sulfur disproportionation pathways, we propose that typically, one would expect that sulfate is the isotopically heaviest pool, and that any other missing sulfur intermediates would likely have lighter values, resembling more the isotope composition of sulfide. In

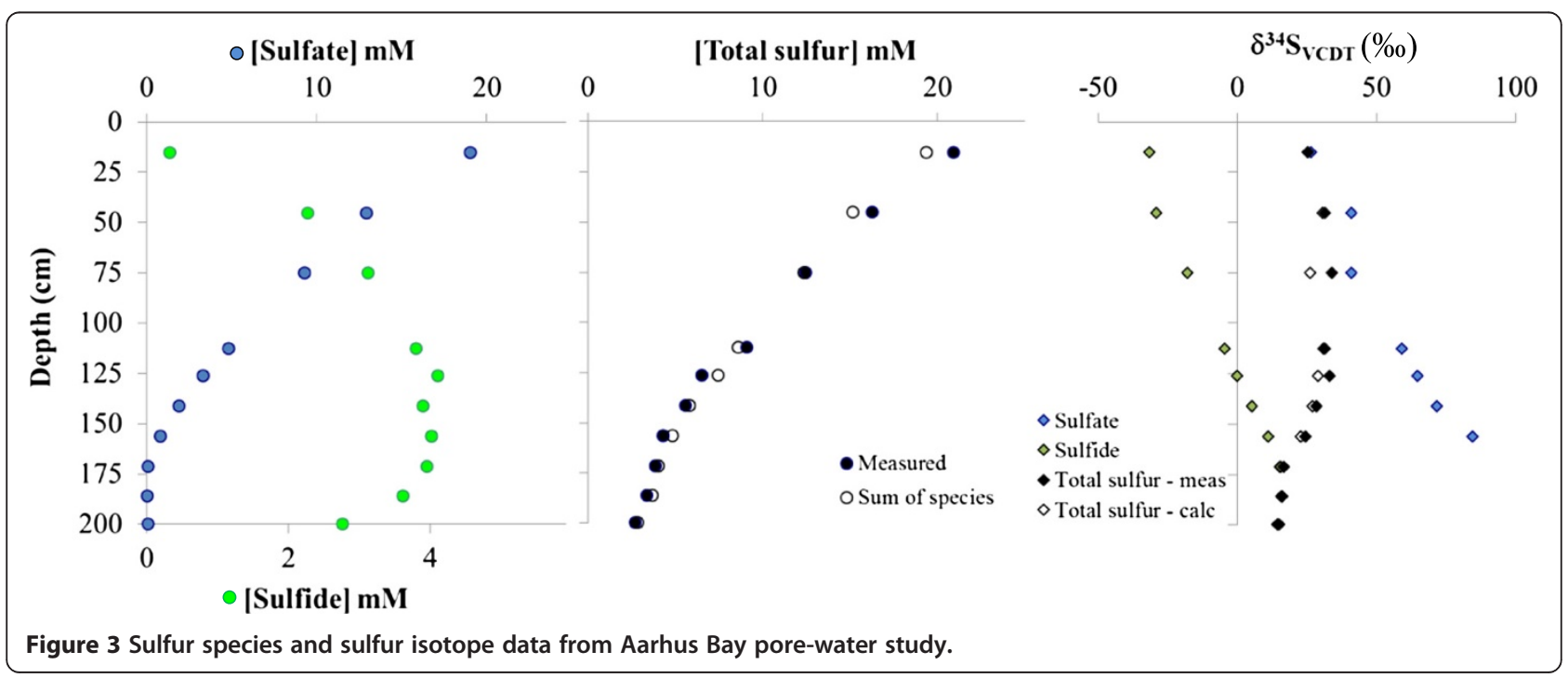




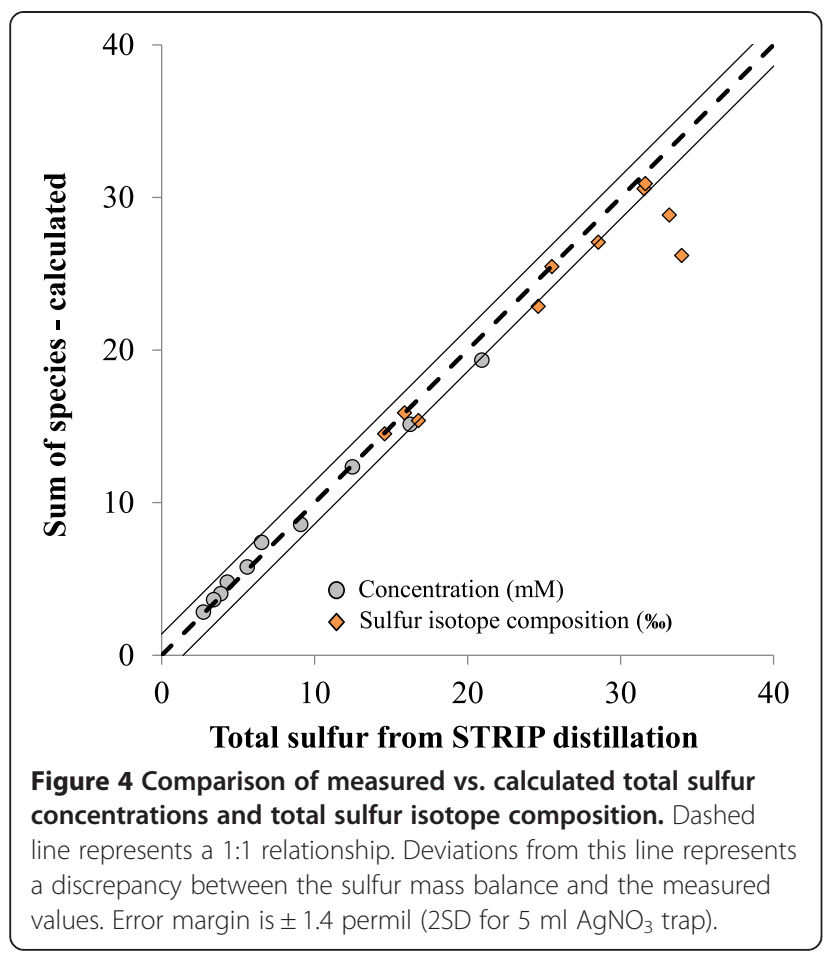

such a case the $\delta^{34} S_{\text {TSmeas }}$ should be lighter than the $\delta^{34} \mathrm{~S}_{\mathrm{TS} \text { calc }}$, again the opposite of what is observed.

The use of a smaller (5 ml) $\mathrm{AgNO}_{3}$ trap in the STRIP distillation (Table 3), as was used in the Aarhus Bay study, tends to yield heavier $\delta^{34} \mathrm{~S}_{\mathrm{TSmeas}}$, and is likely the cause for the offset in the data. In addition, although each of the samples in question was distilled on a separate day, three were distilled on the same hot plate (on different days), suggesting that the poor data quality might also be due to a lower distillation temperature or loss of $\mathrm{H}_{2} \mathrm{~S}$ from the assembly. This finding highlights the importance of good temperature control for the distillation assemblies and for the use of a larger, at least $10 \mathrm{ml}, \mathrm{AgNO}_{3}$ trap.

Table 8 Measured vs. calculated sulfur pools for the Aarhus Bay pore-water study

\begin{tabular}{cccccc}
\hline $\begin{array}{c}\text { Sample } \\
\text { ID }\end{array}$ & $\begin{array}{c}\text { Depth } \\
(\mathbf{c m})\end{array}$ & $\begin{array}{c}\text { Total } \\
\text { sulfur }(\mathbf{m M})\end{array}$ & $\begin{array}{c}\text { Sum of } \\
\text { species }(\mathbf{m M})\end{array}$ & $\begin{array}{c}\mathbf{\delta}^{\mathbf{3 4}} \mathbf{S}_{\text {TSmeas }} \\
\mathbf{\% o}\end{array}$ & $\begin{array}{c}\mathbf{\delta}^{\mathbf{3 4}} \mathbf{S}_{\text {TScalc }} \\
\mathbf{\%} \text { o }\end{array}$ \\
\hline 1 & 15.0 & 20.9 & 19.3 & 25.5 & 25.5 \\
2 & 45.0 & 16.2 & 15.1 & 31.5 & 30.6 \\
3 & 75.0 & 12.5 & 12.4 & 34.0 & 26.2 \\
4 & 112.3 & 9.1 & 8.6 & 31.6 & 30.9 \\
5 & 126.0 & 6.5 & 7.4 & 33.2 & 28.9 \\
6 & 141.0 & 5.6 & 5.8 & 28.5 & 27.1 \\
7 & 156.0 & 4.3 & 4.8 & 24.6 & 22.9 \\
8 & 171.0 & 3.8 & 4.0 & 16.8 & 15.4 \\
9 & 185.8 & 3.4 & 3.6 & 15.9 & 15.9 \\
10 & 199.5 & 2.7 & 2.8 & 14.6 & 14.5 \\
\hline
\end{tabular}

The STRIP distillation of the final filtrate of the series $\mathrm{v}$ samples did not yield any sulfur, which in combination with the good match between the total sulfur and sum of all species profiles demonstrates that there is no major "missing sulfur pool" in the pore-water constituents at station M1 in the Aarhus Bay.

\section{Summary and conclusions}

The STRIP distillation method remains a highly useful technique, with many applications. Although there are other options, like MC-ICPMS, for the sulfur isotope analysis of complex matrix samples of very low sulfur content, the STRIP distillation method provides a straightforward, easily accessible technique. In addition, the use of this method to convert ${ }^{35} \mathrm{~S}$-sulfate tracer to ${ }^{35} \mathrm{~S}$-sulfide tracer has immediate application in the elucidation of newly hypothesized and yet to be discovered sulfur intermediate pathways in microbial sulfur cycling. The potential exists to produce isotopically labeled elemental sulfur, as $\mathrm{H}_{2} \mathrm{~S}$ is known to oxidize to elemental sulfur in the condensing column in the presence of nitrate [6], either by using the generated radiolabeled $\mathrm{H}_{2} \mathrm{~S}$ or by using a modification of the STRIP distillation method to produce directly elemental sulfur. Stable isotope enriched elemental sulfur $\left({ }^{34} \mathrm{~S}\right.$-elemental $\left.\mathrm{S}\right)$ is commercially available, but there is no such supply available for ${ }^{35}$ S-elemental sulfur. The STRIP distillation is also a powerful tool when applied towards total sulfur or in sequential combination with other extraction techniques where it can be used to complete the sulfur mass balance of a sample or system. Over the decades, many adjustments and variations of this method have been employed and the future utility of the STRIP distillation method, especially in the field of sulfur (isotope) biogeochemistry remains strong and promising.

Competing interests

The authors declare that they have no competing interests.

\section{Authors' contributions}

GLA carried out most experiments and drafted the manuscript with input from all authors. GLA and BB designed the experiments and interpreted the results. IAM measured the sulfur intermediate species and assisted with Aarhus Bay study sample collection. HR managed the logistics for the Aarhus Bay study, assisted Aarhus Bay study sample collection and contributed the major sulfur species concentration measurements. All authors read and approved the final manuscript.

\section{Acknowledgements}

We thank J. Pedersen, K. Bomholt-Henriksen, K. K. Imhoff, and T. Max for analytical work and technical support. We especially thank Captian T. Vang and the RV Tyra of Aarhus University for outstanding support for the Aarhus Bay sampling. GLA especially thanks B. B. Jørgensen and T. Ferdelman for their support to re-develop and publish this updated method in the scope of sulfur isotope biogeochemical applications. This work was supported by Max Planck Society (GLA, BB, and IAM), the Deutsche Forschungsgemeinschaft (through the MARUM Center for Marine Environmental Sciences, IAM), the European Research Council under the European Union's Seventh Framework Programme (FP7/2007-1013)/ 
ERC grant agreement no. 294200 (GLA) and co-funded by the Danish National Research Foundation (BB, HR)

\section{Author details}

${ }^{1}$ Max Planck Institute for Marine Microbiology, 28359 Bremen, Germany. ${ }^{2}$ Center for Geomicrobiology, Department of Bioscience, Aarhus University, 8000 Aarhus, Denmark. ${ }^{3}$ Department of Geological Sciences, University of Texas at El Paso, El Paso, TX, USA.

\section{Received: 30 September 2013 Accepted: 10 April 2014}

Published: 22 April 2014

\section{References}

1. Holmkvist $L$, Ferdelman $T G$, Jørgensen BB: A cryptic sulfur cycle driven by iron in the methane zone of marine sediment (Aarhus Bay, Denmark). Geochim Cosmochim Acta 2011, 75:3581-3599.

2. Milucka J, Ferdelman TG, Polerecky L, Franzke D, Wegener G, Schmid M, Lieberwirth I, Wagner M, Widdel F, Kuypers MMM: Zero-valent sulphur is a key intermediate in marine methane oxidation. Nature 2012, 491:541-546.

3. Pfeffer $C$, Larsen S, Song J, Dong M, Besenbacher F, Meyer RL, Kjeldsen KU, Schreiber L, Gorby YA, El-Naggar MY, Leung KM, Schramm A, Risgaard-Petersen N, Nielsen LP: Filamentous bacteria transport electrons over centimetre distances. Nature 2012, 491:218-221.

4. Lever MA, Rouxel O, Alt JC, Shimizu N, Ono S, Coggon RM, Shanks WC, Lapham L, Elvert M, Prieto-Mollar X, Hinrichs K-U, Inagaki F, Teske A: Evidence for microbial carbon and sulfur cycling in deeply buried ridge flank basalt. Science 2013, 339:1305-1308.

5. Luke CL: Determination of total sulfur in rubber. Ind Eng Chem 1943, 15:602-604.

6. Pepkowitz L, Shirley E: Microdetection of sulfur. Anal Chem 1951, 23:1709-1710.

7. Thode H, Monster J, Dunford H: Sulphur isotope geochemistry. Geochim Cosmochim Acta 1961, 25:159-174

8. Forrest J, Newman L: Silver-110 microgram sulfate analysis for the short time resolution of ambient levels of sulfur aerosol. Anal Chem 1977, 49:1579-1584

9. St Lorant I: A new colorimetric microchemical method for determination of sulfur in sulfides, sulfates, etc. Z Physiol Chem 1929, 185:245-266.

10. Shan $X$, Chen B: Determination of carbon-bonded sulfur in soils by hydriodic acid reduction and hydrogen peroxide oxidation. Fresenius $J$ Anal Chem 1995, 351:762-767.

11. Norwitz G: Spectrophotometric determination of sulfate in propellants and nitrocellulose. Philadelphia, PA: Frankford Arsenal; 1970.

12. Kiba T, Tagaki T, Yoshimura Y, Kisha I: Tin (II)-strong phosphoric acid. A new reagent for the determination of sulfate by reduction to hydrogen sulfide. Bull Chem Soc Jpn 1955, 28:641-644.

13. Ueda A, Sakai H: Simultaneous determinations of the concentration and isotope ratio of sulfate- and sulfide-sulfur and carbonate carbon in geological samples. Geochem J 1983, 17:185-196.

14. Coleman ML, Moore MP: Direct reduction of sulfates to sulfur dioxide for isotopic analysis. Anal Chem 1978, 50:1594-1595.

15. Johnston DT, Farquhar J, Canfield DE: Sulfur isotope insights into microbial sulfate reduction: when microbes meet models. Geochim Cosmochim Acta 2007, 71:3929-3947.

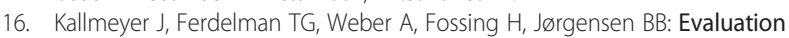
of a cold chromium distillation procedure for recovering very small amounts of radiolabeled sulfide related to sulfate reduction measurements. Limnol Oceanogr Methods 2004, 2:171-180.

17. Gröger J, Franke J, Hamer K, Schulz HD: Quantitative recovery of elemental sulfur and improved selectivity in a chromium-reducible sulfur distillation. Geostand Geoanalytical Res 2010, 33:17-27.

18. Alford SE, Alt JC, Shanks WC III: Sulfur geochemistry and microbial sulfate reduction during low-temperature alteration of uplifted lower oceanic crust: insights from ODP Hole 735B. Chem Geol 2011, 286:185-195.

19. Fossing $H$, Jørgensen BB: Measurement of bacterial sulfate reduction in sediments: evaluation of a single-step chromium reduction method. Biogeochemistry 1989, 8:205-222.

20. Zerkle AL, Kamyshny A Jr, Kump LR, Farquhar J, Oduro H, Arthur MA Sulfur cycling in a stratified euxinic lake with moderately high sulfate: constraints from quadruple S isotopes. Geochim Cosmochim Acta 2010, 74:4953-4970
21. Sim MS, Bosak T, Ono S: Large sulfur isotope fractionation does not require disproportionation. Science 2011, 333:74-77.

22. Révész K, Coplen TB: Determination of the $\delta(34 S / 32 S)$ of low-concentration sulfate in water: RSIL lab code 1949. In Book 10 Methods Rest Stable Isot Lab. ; 2007.

23. Turchyn AV, Tipper ET, Galy A, Lo J-K, Bickle MJ: Isotope evidence for secondary sulfide precipitation along the Marsyandi River, Nepal, Himalayas. Earth Planet Sci Lett 2013, 374:36-46.

24. Kang P-G, Mayer B, Mitchell MJ: Comparison of sample preparation methods for stable isotope analysis of dissolved sulphate in forested watersheds. Isotopes Environ Health Stud 2012, 48:410-420.

25. Paris G, Sessions AL, Subhas AV, Adkins JF: MC-ICP-MS measurement of $\delta 34 S$ and $\Delta 33 \mathrm{~S}$ in small amounts of dissolved sulfate. Chem Geol 2013 345:50-61.

26. Lin A-J, Yang T, Jiang S-Y: A rapid and high-precision method for sulfur isotope $\delta 34 \mathrm{~S}$ determination with a multiple-collector inductively coupled plasma mass spectrometer: matrix effect correction and applications for water samples without chemical purification. Rapid Commun Mass Spectrom 2014, 28:750-756

27. Craddock PR, Rouxel OJ, Ball LA, Bach W: Sulfur isotope measurement of sulfate and sulfide by high-resolution MC-ICP-MS. Chem Geol 2008, 253:102-113.

28. Cífka J: The reduction of S35-labelled sulphates. Int J App/ Radiat Isot 1963, 14:174-176

29. Wotte T, Shields-Zhou GA, Strauss H: Carbonate-associated sulfate: experimental comparisons of common extraction methods and recommendations toward a standard analytical protocol. Chem Geol 2012, 326-327:132-144.

30. Bao HM: Purifying barite for oxygen isotope measurement by dissolution and reprecipitation in a chelating solution. Anal Chem 2006, 78:304-309.

31. Schulz HD, Zabel M: Marine Geochemistry. Berlin Heilelberg: Springer-Verlag; 2006.

32. Cline J: Spectrophotometric determination of hydrogen sulfide in natural waters. Limnol Oceanogr 1969, 14:454-458.

33. Zopfi J, Ferdelman TG, Fossing $H$ : Distribution and fate of sulfur intermediates-sulfite, tetrathionate, thiosulfate, and elemental sulfur-in marine sediments. Geol Soc Am Spec Pap 2004, 379:97-116.

doi:10.1186/1467-4866-15-4

Cite this article as: Arnold et al:: Modern applications for a total sulfur reduction distillation method - what's old is new again. Geochemical Transactions 2014 15:4.

\section{Submit your next manuscript to BioMed Central and take full advantage of:}

- Convenient online submission

- Thorough peer review

- No space constraints or color figure charges

- Immediate publication on acceptance

- Inclusion in PubMed, CAS, Scopus and Google Scholar

- Research which is freely available for redistribution 